\title{
Новая Европа
}

\section{ПОЛИТИКО-ІРАВОВЫЕ ПОСЛЕДСТВИЯ ВСТУПЛЕНИЯ РОССИИ В СОВЕТ ЕВРОПЫ}

\author{
М.Л. Э н т и н *
}

Заявха на вступление в Совет Европы была подана Российской Федерацией слишком давно. С какого-то момента обретение полноправного членства для российского истэблишмента сделалось самоцелью. Дипломатические усилия, направленные на решение однажды поставленной задачи, предпринимались зачастую в инерционном режиме. Серьезный анализ политико-правовых последствий вступления не предпринимался.

Свидетельств тому более чем достаточно.

Во-первых, подавляющее большинство населения, как, впрочем, и журналистов, юридической общественности, государственного аппарата, политического класса, остается в неведении относительно того, что из себя представляет международная организация, принявшая Россию в свои ряды.

Значительную часть огромного числа газетных публихаций и телепередач, появившихся в стране буквально накануне и сразу же после приема в Совет Европы, трудно охарактеризовать иначе, нежели домыслы, фантазии или откровенная дезинформация. Чего стоят, например, широко разошедшиеся уверения в том, что заключенным теперь будет выплачиваться по 10 американских долларов в день, что из госказны на возвращение депортированных во времена сталинского режима надо будет изыскать миллиарды рублей («Московский комсомолец»), что ратовавшие за полноправное членство продались отечественной орппеступности и наркомафии, заинтересованным в скорейшей отмене смертной казны (А. Невзоров), что теперь все потерпевшие могут обрашаться в Европейские Комиссию и Суд по правам человека.

* Дохтор юридических наук, первый заместитель директора Департамента общеевропейского сотрудничества МИД РФ (подробно об авторе см. наш журнал № 3 за 1995 г.). 
Во-вторых, добиваясь вступления в Совет Европы, российское руководство основную ставку сделало на использование методов силового давления. Работе внутри страны по приведению законодательства и правоприменительной практики в соответствие с уставными требованиями организации уделялось заведомо недостаточное внимание.

Все страны ЦВЕ вслед за подачей заявки на вступление приступали к осуществлению специальных программ адаптации национального правового порядка к стандартам Совета Европы. В России такая программа даже не была. намечена. Соответствующие задачи были сформулированы уже после вступления ${ }^{1}$. А подготавливающие прием России инстанции Совета раз за разом констатировали: систематические нарушения прав человека продолжаются, до установления господства права очень и очень далеко 2 .

В-третьих, и в концептуальном, и в организационном плане обретение полноправного членства явилось для России желанной неожиданностью. Российская внешнеполитическая доктрина лишь вскользь упоминает полезную роль, которую Совет Европы мог бы играть в обеспечении стабильности и безопасности на континенте. Но какое место ему отводится в контексте разделения труда мехду основными европейскими (евроатлантическими) организациями, не уточняется. То, каким образом Россия собирается продвигать в структурах Совета свои национальные интересы, еще хдет своего осмысления.

Точно так же государственные институты, способные обеспечить новое качество участия в деятельности Совета, начали создаваться с серьезным опозданием. Вопрос о приеме был фактически предрешен уже в январе 1996 года, после того как Парламентская ассамблея сняла свои возражения. Однако структуры координации деятельности органов государственной власти по работе с Советом Европы и выполнению обязательств, вытекающих из членства, как внутри страны, так и за рубежом стали формироваться лишь к лету 1996 года.

С учетом этого в настоящей статье в большей степени предпринимается попытка заполнить вакуум политико-правовой информации о вступлении России в СЕ, нежели предложить системное видение его политико-правовых последствий.

Исторический экскурс: перипетии вступления. Сближение с Советом Европы наметилось еще в эру М.С. Горбачева. До этого старейшая и авторитетнейшая организация континента удостаивалась в основном ругательных эпитетов. Страсбург был избран в качестве трибуны для популяризации идеи жединого европейского дома» - визит М.С. Горбачева и его выступление на сессии ПАСЕ явились ярчайшим событием в ее истории. Со своей стороны, спе- 
циально для СССР Совет Европы изобрел статус «специально приглашенного» государства. Такой статус позволял весомо участвовать в деятельности Парламентской ассамблеи, а затем и других органов СЕ, за исключением Комитета министров, без права решаюшего голоса. Кроме того, Советский Союз присоединился к ряду конвенций СЕ, в том числе Европейской культурной конвенции, участие в которой в прошлом всегда предшествовало полноправному членству.

Российская Федерация унаследовала от СССР как статус «специально приглашенного» и участие в восьми конвенциях СЕ, так и установку на дальнейшее сближение с организацией. Только теперь интеграция в СЕ должна была осуществляться на принципиально иной основе. Россия провозгласила защиту демократических завоеваний, обеспечение прав человека, утверждение господства права главными приоритетами своей внутренней и внешней политики. Эти ориентиры полностью совпадали с целями и принципами функционирования СЕ. Ставка на обретение полноправного членства в организации становилась неотвратимой. 7 мая 1992 г. Россия подала заявку на вступление.

Логично было бы предположить, что в интересах нарождающегося партнерства наша страна будет с распростертыми объятиями принята в «лоно западноевропейской цивилизации». Приверженность единым ценностям, отстаиваемым CE, создавала прочную международно-правовую базу крепнушего сотрудничества. К тому же остальная Европа была объективно заинтересована в том, чтобы привязать Россию к международным демократическим и правозащитным институтам. Ведь основа основ, сама философия создания и функционирования СЕ сводится к формированию в государствахчленах таких политических снсем, такого правового порядка, которые бы препятствовали возврату к тоталитаризму, расцениваемому в качестве единственного истинного источника агрессивных войн, и таким образом к обеспечению через внутренние преобразования мирной жизни на континенте. Благодаря приему в СЕ Западная Европа могла распространить на Россию международные механизмы контроля, эффективность которых была проверена временем.

Однако развитие событий пошло по совершенно иному сценарию. «Розовый период надежд» во взаимоотношениях между Россией и Западом очень быстро закончился. Соблазн косвенной изоляции России через дискриминируюшее ее включение в западные интеграционные и военно-политические структуры бывших союзников по ОВД и европейских стран, возникших на территории бывшего СССР, оказался слишком силен. В рассуждениях о будущем сотрудничества с Россией акцент сместился на гипертрофиро- 
вание «половинчатости», «обратимости», «непоследовательности», «медлительности» реформ, отстаивание тезиса о слабости власти и перманентности разворачивающегося в стране политического кризиса, противопоставление внутренней динамики политических и экономических процессов в России и других бывших социалистических государствах.

В рамках ббщей стратегии Совет Европы занял в отношении России сугубо выжидательную позицию. В 1992-1993 годах до рассмотрения российской заявки, вопреки формальному бещанию тогдашнего Генерального секретаря организации Катрин Лалюмьер закончить процедуру в течение года, вообще не дошло дело. Парламентская ассамблея СЕ направила в Москву и регионы страны несколько команд юридических экспертов (вместо одной, как в случае со всеми другими кандидатами в члены) для подготовки доклада о состоянии правового порядка в Российской Федерации лишь после того, как был «преодолен» конфликт исполнительной и законодательной ветвей власти, принята новая Конституция, проведены вторые свободные парламентские выборы. В феврале 1995 года ПАСЕ приостановила рассмотрение российской заявки из-за войны в Чечне ${ }^{3}$. В целом применительно х России вся процедура носила намеренно мучительный, осложненный многочисленными бюрократическими и политизированными препонами характер.

Как следствие при участии Совета в Европе сложилась чреватая самыми неблагоприятными последствиями ситуация. После того ках в организацию оказались приняты все бывшие противники из распушенной ОВД, кроме России, а также Албания и Македония, страны Балтии, Молдавия и Украина, появление на континенте новых разделительных линий по западной границе нашей страны и отнюдь не символическая изоляция России приобрели вполне зримые очертания. Вместо того чтобы содействовать демохратическим тенденциям в российском обществе через полноправное вовлечение его представителей в свою работу, СЕ, вопреки прокламируемым им лозунгам, на практике способствовал ослаблению и дезориентации демохратических сил в России, росту антизападных настроений.

В этих условиях по инициативе руховодства Франции и Германии, подсказанной российскими дипломатами и политиками, Европейский Союз (т.е. ядро $\mathrm{CE}$ ) - как только для этого возникли минимальные предпосылки в связи с началом процесса мирного урегулирования в Чечне - принял волевое решение как можно скорее включить Россию в Совет Европы вне зависимости от дальнейшего развития внутриполитической ситуации в стране ${ }^{4}$. На депутатов ПАСЕ и парламентские круги европейских государств 
было оказано беспрецедентное давление. Одновременно отчетливо замаячила перспектива отзыва Россией обращения о вступлении. В результате сентябрьская 1995 года сессия ассамблеи возобновила рассмотрение российской заявки, а январская 1996 года утвердила на нее позитивное заключение $\mathrm{e}^{5}$. И это несмотря на продолжающиеся широкомасштабные войсковые операции федеральных сил в Чечне, весьма критическое восприятие итогов парламентских н глубоко укоренившиеся опасения по поводу предстоящих президентских выборов. Комитету министров оставалось лишь проштамповать решение о приеме России, что и было сделано без особых проблем спустя две недели.

Таким образом, буквально в последний момент европейским странам и России удалось избежать тяжелейшего кризиса в своих взаимоотношениях, и без того уже отягощенных возможностью расширения НАТО и приближения военной инфраструктуры альянса к нашим западным рубежам.

Совет Европы: общая характеристика. И в структурном, и в функциональном отношении СЕ является чрезвычайно интересной, во многом даже уникальной региональной организацией общей компетенции.

Создан в 1949 году с целью содействия более тесному «европейскому сплочению». Объединяет 39 государств. Кандидаты на вступление- - Армения, Белоруссия, Босния-Герцеговина и Хорватия. Статус наблюдателя предоставлен США, Японии, Канаде и Израилю.

Система главных органов включает Комитет министров, Парламентскую ассамблею, Конгресс местных и региональных властей Европы и Сехретариат.

Комитет министров собирается на уровне министров иностранных дел ках минимум два раза в год. Остальное время работает в составе их постоянных представителей. В своей деятельности опирается на разветвленную сеть вспомогательных органов межправительственного сотрудничества.

Только Комитет министров вправе принимать от имени СE обязательные решения. Утверждаемые им акты облекаются в форму рекомендаций правительствам стран-членов. Наиболее важные решения принимаются консенсусом. Главный итог деятельности подготовка конвенций.

Парламентская ассамблея наделена консультативными функциями, заседает четыре раза в год. Резолюции обычно принимаются абсолютным большинством голосов. Они имеют рекомендательный характер. Ассамблея формирует 13 комиссий (изучается возможность создания еще 3 ).

Конгресс местных и региональных властей Европы создан в соответствии с рекомеңдацией Венской 1993 года встречи глав 
государств и правительств стран-членов СЕ. Провел учредительную сессию в 1994 году. Наделен, как и ПАСЕ, консультативными функциями, заседает один раз в год. Состоит из Палаты регионов и Палаты местных властей. Главные цели - развитие демократии на местах, укрепление трансграничного и межрегионального сотрудничества в Европе.

Cекретариат $C E$ насчитывает около 1100 служаших. Возглавляется Генеральным секпетарем - главным административным лицом организации.

При СЕ имеется большая группа организачий-саттелитов с самостоятельным бюджетом, правовой основой создания и функционирования которых служат Частичные соглащения.

В деятельности СЕ очень велик удельный вес межпарламентского сотрудничества. Причем особый смысл тахого сотрудничества заключается не в обсуждении и подготовке тех или иных решений резолюции ПАСЕ имеют рекомендательный характер, не в консолидации общественного мнения континента - голос других международных форумов звучит зачастую намного весомее, а в утверждении своего рода политической и культурной принадлежности, формировании некоей европейской общности всех тех, кто участвует в работе ассамблеи или имеет к ней отношение.

Еше одной весьма своеобразной чертой в деятельности СЕ можно считать все возрастающее внимание к межрегиональному сотрудничеству и проблематике местного самоуправления. При помощи одного из своих главных органов - Конгресса местных и региональных властей Европы - Совет позволяет городам, районам, областям стран-членов развивать прямые связи без патронажа центральных правительств.

Наконец, главная отличительная особенность Совета Европы состоит в том, что его наиболее именитые, снискавшие ему известность и уважение структуры вынесены за рамки организации. Европейские Комиссия и Суд по правам человека независимы от Совета Европы. Они находятся вне системы его главных органов, не упоминаются в его уставных документах (хотя и связаны с ними сотнями нитей) и обслуживают совершенно конкретный международно-правовой акт - Европейскую конвенцию о зашите прав человека и основных свобод (ЕКПЧ). Заслуга СЕ - в создании регионального механизма контроля за выполнением государствами своих обязательств по зашите прав человека. Но приписывать ему успех функционирования механизма было бы не совсем корректно. На практике, однако, именно это и происходит. В бшественном мнении СЕ отождествляется прежде всего с эффективной защитой прав человека. И сам Совет усиленно культивирует эти представления. 
Европейские Комиссия и Суд без каких-либо преувеличений можно охарактеризовать как главное достояние СЕ. Вместе с Комитетом министров - еще одним элементом триады - они обеспечивают формирование единого европейского пространства в том, что касается утверждения принципов господства права, плюралистической демократии и уважения $\mathbf{x}$ свободе человеческой личности ${ }^{6}$.

Это происходит следуюшим образом. По исчерпании внутренних средств правовой защиты любое физическое или юридическое лицо, находящееся под юрисдикцией государства - участника ЕКПЧ, имеет возможность обратиться с жалобой в Европейскую комнссию по правам человека. В случаях, когда жалоба принимается $\mathrm{K}$ рассмотрению, комиссия сначала пытается добиться полюбовного урегулирования. Если ее усилия оказываются безрезультатными, она подготавливает доклад с описанием фактологической и юридической стороны дела. В нем обосновывается заключение относительно того, были ли нарушены положения ЕКПЧ. При констатации нарушения предлагаются конкретные меры, направленные на восстановление прав личности и/или предоставление потерпевшему справедливой компенсации.

В течение трех месяцев для окончательного решения дело может быть передано в Европейский Суд по правам человека. По прошествии указанного срока оно автоматически направляется в Комитет министров'.

Исполнение решений возлагается на государство-ответчика. Контроль за исполнением поручен Комитету министров. Как общее правило, проигравшее дело государство старается не оспаривать вынесенный вердикт. Со своей стороны, Комитет министров не снимает дело с контроля вплоть до наллежащего выполнения решения.

Рассмотрение Европейскими Комиссией и Судом конкретных дел по своему политико-правовому значению далеко выходит за рамки восстановления нарушенного права отдельных лиц или организаций. Фактически в заключениях и решениях дается правовая квалификация состоятельности тех или иных законодательных актов государств-членов СЕ и/или практики их применения с точки зрения соответствия нормам ЕКПЧ, вынуждающая национальные власти осуществлять иногда весьма серьезные корректировки правового порядка. Конкретные примеры: в целом ряде стран были отменены законы, закрепляющие дискриминацию неграждан, оставляющие лазейки для использования принудительного труда, ограничивающие свободу въезда и выезда и т.д., внесены изменения в уголовное, уголовно-процессуальное и уголовно-исправительное законодательство, ограничена свобода рук полиции и спецслужб, расширены возможности судебного разбора. 
В итоге при помоши регионального механизма контроля за соблюдением государствами своих обязательств удалось получить впечатляющие результаты. Во-первых, все участники ЕКПЧ стали внимательно следить за эволюцией прецедентного права, формируемого Европейскими Комиссией и Судом; отладили механизмы сопряжения национального законотворческого процесса с эволюцией европейских стандартов в области защиты прав человека; при работе по совершенствованию законодательства предпочли заранее ориентироваться на выводы контрольных органов. Во-вторых, были созданы необходимые предпосылки для формирования единого правового пространства с общей правовой культурой и сходными правовыми традициями, не препятствуюшего сохранению социокультурной самобытности и своеобразия национальных правовых решений. В-третьих, страны-члены были вынуждены уделять неослабное внимание правозащитной проблематике, работая на создание таких внутригосударственных условий, при которых подача жалоб в международные инстанции стала бы ненужной, превратилась в исключение из правила. В-четвертых, активная деятельность Европейских Комиссии и Суда превратилась в еще один влиятельный фактор набирающих силу интеграционных процессов. Кахдое из государств--участников ЕКПЧ в какой-то момент перехило своего рода правовую революцию, расставаясь с ключевым в прошлом представлением о том, что решение высших национальных судебных и законодательных органов окончательно и обжалованию не подлежит. На практике в том, что касается обеспечения прав человека, правовые системы стран-участниц ЕКПЧ полностыю интегрированы в единый европейский правопорядок. Наконец, впятых, стали достоянием истории представления об абстрактной значимости проблематики прав человека, ее оторванности от экономики и больших денег. Ведь в сфере прав человека сейчас находятся такие вопросы, как право частной собственности, национализация, доступ к образованию, спутниковое теле- и радиовешание, свобода осуществления информационной и рекламной политики и т.д..$^{8}$

Пока права человека остаются главным направлением в деятельности СЕ. Вместе с тем за последние годы среди ее приоритетов существенно вырос удельный вес программ содействия странам ЦВЕ и СНГ, чрезвычайно большое значение приобрели вопросы разрешения межнациональных, межэтнических и межгосударственных противоречий, постконфликтной реабилитации регионов, поиска ответов на современные вызовы человечеству.

С конца 80-х годов СЕ стрсмительно расширяет свой состав за счет стран ЦВЕ, а затем и СНГ. По характеру своего правового и институционного развития, по состоянию дел в правозащитной 
сфере многие из них явно не дотягивают до стандартов организации. Прием осушествляется в качестве аванса и диктуется прежде всего интересами политической целесообразности. Поэтому СЕ, обретая второе дыхание, бросает свои ресурсы на содействие молодым демократиям. Запускаются многосторонние и двусторонние программы сотрудничества, ориентированные на охазание помощи в создании правозашитных структур, укреплении демократических институтов, переподготовке кадров, формировании нормативной базы местного самоуправления. Особенно большое внимание CE уделяет содействию Албании и странам Балтии, несколько позже Молдавии и Украине.

В настоящее время одна из крупнейших подобного рода программ осуществляется в отношении Российской Федерации. Частично она финансируется на средства Европейского Союза. За двухлетний период предполагается истратить порядка 6 млн. долл. США. Первый транш, выделенный в феврале 1996 года, составил около 1,5 млн. долл.

Программа состоит из шести проектов. Первые два связаны с проблематикой федерализма и местного самоуправления. Третий призван помочь становлению федеральной и областных комиссий по правам человека. Проекты с четвертого по шестой обслуживают проведение второго этапа правовой реформы в нашей стране. О6щая целевая направленность программы - подготовить условия, при которых национальное законодательство и правоприменительная практика не противоречили бы нормам ЕКПЧ и других основополагающих конвенций организациия.

Концептуально программы содействия молодым демократиям тесно связаны с новейшей идеологией Совета Европы, провозглашенной Венской 1993 года встречей глав государств и правительств стран-членов. Ее суть - в признании за СЕ ключевой роли в становлении на континенте системы демократической безопасности.

В последние годы СЕ стремительно наращивает политические мускулы. Практически любые вопросы европейской повестки дня активно дебатируются Парламентской ассамблеей. Депутатами ПАСЕ обсуждаются имплементация Дейтонских соглашений, кипрское урегулирование, ситуация в Турции, Чечне и т.д. ${ }^{10}$

От диалога по узловым вопросам мировой политики организация все настойчивее переходит к поискам практических решений. Она участвует в подтотовке конституции БиГ, создании параллельных национальных правозащитных судебных структур, рассчитывает осуществлять контроль за этнической политикой Хорватии.

Венский саммит дал мощный импульс работе СE в области защиты национальных меньшинств. Была подготовлена и открыта к подписанию соответствующая Рамочная конвенция. В настоящее 
время разрабатываются механизмы международного контроля за ее соблюдением.

Растущая активность СЕ в указанных сферах несколько заслоняет многопрофильность ее деятельности. Ведь СE - региональная организация общей компетенции. Она занимается также вопросами экономического, культурного, научно-технического сотрудничества. Большое внимание уделяется социальной сфере. Много делается для расширения молодежного обмена. Очень интересны наработки, касающиеся сотрудничества по линии СМИ, и т.д.

На все это обращалось особенно большое внимание при обсуждении в Государственной Думе и Совете Федерации Федерального Собрания законопроектов о присоединении России к Уставу СЕ. В частности, подчеркивалось, что в рамках СЕ действует порядка 160 многосторонних конвенций, присоединение к которым равносильно заключению около 40 тыс. двусторонних договоров. Конкретно присоединение к конвенциям в области образования поможет России обеспечить взаимное признание вузовских дипломов. Присоединение к ряду уголовно-правовых конвенций поможет в борьбе с терроризмом, незаконным оборотом наркотиков, отмыванием доходов от преступной деятельности, декриминализации общества...

\section{Политико-правовые последствия вступления}

Обязательства, вытекаючие из иленства. В правовом отношении вступление России в Совет Европы оформлено двумя типами документов. 8 февраля 1996 г. Комитет министров Резолюцией 2(96) пригласил Российскую Федерацию стать членом СЕ, дав при этом косвенную отсылку х заключению ПАСЕ № 193 (1996) по заявке России на вступление от 25 января 1996 г. Со своей стороны, Россия приняла приглашение, осуществив все необходимые процедуры присоединения к СЕ и подписав его основополагающие конвенции.

В рамках церемонии вступления 28 февраля 1996 г. министр иностранных дел России передал Генеральному секретарю СЕ ахты о присоединении к Уставу организации (было осушествлено путем принятия федерального закона), Генеральному соглашению о привилегиях и иммунитетах $\mathrm{CE}$ и протокояов $\mathrm{K}$ нему. Состоялось подписание ЕКПЧ и большинства протоколов $\mathbf{x}$ ней, Европейской конвенции о запрещении пыток и бесчеловечного или унижающего достоинство обращения или наказания и протоколов к ней, Рамочной конвенции о защите национальных меньшинств, Европейской хартии местного самоуправления. Министр сделал также устное заявление о намерении при ратификации признать в законодатель- 
ном порядке право на подачу индивидуальных жалоб в Европейскую комиссию по правам человека и обязательную юрисдикцию Европейского Суда по правам человека и о совместимости обязательств Российской Федерации по правозащитным конвенциям СЕ и $\mathrm{CH \Gamma}$.

С точки зрения действующего международного права заключение ПАСЕ о заявке России, давшее «зеленый свет» соответствующей резолюции Комитета министров, не имеет обязательной силы. В Уставе СЕ прямо зафиксировано, что резолюции ассамблеи имеют рекомендательный характер.

По Уставу полномочия Комитета министров выносить юридически обязательные решения также сушественно ограничены. Принимаемые им резолюции, как общее правило, направлены лишь на согласование политики государств-членов. Но в том, что касается вопросов внутренней организации, бюджета, приема в члены организации или исключения, резолюции Комитета министров имеют юридически обязательный характер.

В упоминавшейся Резолюции 2(96) говорится: Комитет министров постановляет «пригласить Российскую Федерацию стать членом Совета Европы и присоединиться к его Уставу... в свете принятых обязательств и заверений относительно их выполнения, данных российскими властями в ходе контактов как с Комитетом министров, так и с Парламентской ассамблеей Совета Европы в целях вступления в Совет Европы». Поскольку перечень таких обязательств и заверений содержится в заключении ПАСЕ, Комитет министров своей резолюцией фактически придает рекомендациям ассамблеи уже не просто морально-политическое, но и определенное политико-правовое значение.

Это политико-правовое значение суцественно усиливается фактом присоединения России к Совету Европы на основании положений приглашения Комитета министров, среди которых есть отсылка и к мнению ПАСЕ. Важно также учитывать, что как при подготовке заключения, так и при утверждении приглашения были приняты во внимание обешания, данные ассамблее руководством России, под которыми стоят подписи Президента Б.Н. Ельцина, премьер-министра В.С. Черномырдина, тогдашних спикеров Государственной Думы и Совета Федерации Федерального Собрания И.П. Рыбкина и В.Ф. Шумейко. Большой личный вклад в обеспечение положительного голосования по российской заявке внесли члены делегации Федерального Собрания в ПАСЕ - лидеры крупнейших российских политических партий Г.А. Зюганов, В.П. Лукин, В.В. Жириновский...

Оба эти фактора позволяют отнести документы, оформляюшие членство России в СE, к категории актов политически обязываю- 
щего характера или даже актов так называемого «мягкого международного права». Оба эти понятия получили широкое распространение в доктрине мехдународного права в связи с необходимостью адаптации нормативной системы, регулирующей международные отношения, к практике их применения. Акты политически обязывающего характера принимаются и ОБСЕ, и некоторыми другими мехдународными структурами. Они не содерхат и не создают нормы международного права. Однако это не препятствует государствам настаивать на необходимости их последовательного соблюдения и применять в этих целях различные формы политического, экономического и иного давления или даже принуждения.

Поэтому для юридической квалификации тех или иных мехдународных актов в качестве содержащих морально-политические обязательства или же имеющих также политико-правовое значение прежде всего важно посмотреть, в какой степени государства намерены добиваться их соблюдения, хакие для этих целей создаются механизмы контроля. Одновременно следует учитывать ангажированность конкретного государства на выполнение принимаемых на себя обязательств.

В рамках Совета Европы действует трехуровневый механизм контроля за соблюдением государствами своих обязательств. Наиболее жесткий — конвенционный, созданный на базе ЕКПЧ (он описывается выше). Его задействование в отношении России возможно только после ратификации конвенции.

Внесудебный контроль стремятся осушествлять два органа Комитет министров и Парламентская ассамблея. До недавнего времени разработанные ими процедуры контроля имели весьма аморфный характер. Их применение давало весьма небольшую отдачу.

В последние годы механизмы контроля были усилены. Так, ключевым комиссиям ПАСЕ поручен постоянный мониторинг за правозащитной ситуацией и становлением правового государства в странах, недавно вступивших в члены организации. Вопросы соблюдения ими принятых на себя обязательств постоянно вносятся в повестку дня сессий ПАСЕ. Подготавливаются изменения в правилах процедуры, которые бы позволили упростить применение санкций $\mathrm{K}$ государствам, нарушающим уставные требования СE, в виде приостановки полномочий парламентских делегаций. Но даже без применения санкций сам факт жесткой публичной критики может быть весьма неприятен.

На вооружении Комитета министров имеются процедуры регулярного ббзора соблюдения государствами уставных требований. Кроме того, в обязанности Генерального сехретаря входит подготовка соответствуюших докладов. Они должны представляться раз в два года. Возможно использование и чрезвычайной процедуры. 
Крайней мерой воздействия является исключение государства из членов организации. Окончательное решение принимается Комитетом министров. В какой-то степени оно может быть инициировано и Парламентской ассамблеей.

В практике СЕ лишь дважды угроза исключения становилась вполне реальной. В первом случае Греция «черных полковнихов" поспешила выйти из состава $\mathrm{CE}$ за день до исключения. Во втором - входящие в СЕ государства предпочли не исключать Турцию после происшедшего там военного переворота, чтобы не утратить каналы воздействия на эту страну.

Таким образом, можно констатировать, что СЕ обладает достаточно мощными рычагами как морально-политического и психологического, так и организационного и политико-правового давления на свпих членов в целях выполнения ими уставных обязательств. В этих условиях главным становится уже не столько вопрос о том, являются ли рекомендации ПАСЕ нормами рекомендательного, морально-политического или юридически обязывающего характе$\mathrm{pa}$ сколько наличие политической воли государств добиваться их соблюдения.

Содержащиеся в заключении ПАСЕ по российской заявке рекомендации можно схематично подразделить на три группы. К первой относятся те из них, в которых дается перечень важнейших конвенций CE, без участия в которых полноправное членство все равно остается неполным, усеченным, а также желательные сроки их подписания и ратифихации. Поскольку Россия вступила в Совет Европы в целях максимально эффективного участия в деятельности организации, она объективно заинтересована в том, чтобы поставить эти конвенции на службу своей интеграции в Европу и осуществления внутренних реформ. Вполне естественно, что уже в рамках официальной церемонии вступления министр иностранных дел России подписал не только ЕКПЧ, но и целый ряд других основополагающих конвенций СE, что не являлось обязательным условием для оформления членства. Более того, можно ожидать, что уже к лету 1996 года будет разработана и запущена федеральная программа совершенствования захонодательства и правоприменительной практики в соответствии со стандартами СЕ, ориентированная на то, чтобы правовой порядок в России не противоречил нормам этих хонвенций, включая ЕКПЧ.

Вторую группу образуют рекомендации, касающиеся продолжения уже осушествляемых в России преобразований. В частности, в них идет речь о проведении судебной реформы, изменении функций прокуратуры, гарантиях адвокатам, улучшении условий в тюрьмaх и других местах лишения свободы. Все эти рехомендации идентифицируют области внутренней жизни нашей страны, кото- 
рые вызывают наибольшую озабоченность с точки зрения европейских стандартов. Характерно, что среди них нет ни свободы совести, ни свободы вероисповедания, ни свободы СМИ. Но ведь эту озабоченность в полной степени разделяют и авторы правовой реформы, и политические партии России, и население страны. Балее того, большинство из них полностью покрываются программными положениями ныне действующей Конституции. В частности, в ней закрепляется перспектива отмены смертной казни (ст. 20), введение альтернативной гражданской службы и т.д. Поэтому последовательное выполнение таких рекомендаций прежде всего в наших собственных интересах.

Несколько иная ситуация в отношении третьей группы рекомендаций. K ним могут быть отнесены все те, которые касаются вопросов внешней политики (вывод войск из Молдавии, осуждение концепции «ближнего зарубежья», реституция культурных ценностей и др.) или сформулированы нарочито вызывающе и расплывчато. При их анализе важно учитывать, что они в, большей степени сигнализируют о наличии нерешенных проблем в отношениях между Россией и остальными европейскими странами. Подход $\mathrm{k}$ их выполнению требует учета требований взаимности, практики других государств, имеющихся у России мехдународно-правовых обязательств и норм действующего международного права ${ }^{11}$.

Заключение. Даже краткий анализ того, как протекало вступление России в Совет Европы, особенностей и структуры этой организации, а также обязательств, вытекающих из членства, свидетельствует о том, насколько разнообразны его политико-правовые последствия. Однако общий вывод может быть только один бретение полноправного членства дает России исторический шанс на сближение с остальной Европой, возможность гораздо более массированного и эффективного влияния на общеевропейские процессы, дополнительный потенциал оуществления внутренних реформ.

${ }^{1}$ См. п. 3 Распоряжения Президента Российской Федерации X 188 от 13 апреля 1996 г. «О мерах по обеспечению участия Российской Федерации в Совете Европы».

${ }^{2}$ Cм. Док. CE AS/Bur/Rus (1994) 7 от 28 сентября 1994 г. «Доклап о соответствии правопорядка в Российской Федерации нормам Совета Европы»; CE Dос.7443 от 2 января 1991 г. «Доклат Комиссии по политическим вопросам о заявке России на вступление в Совет Европь».

${ }^{3}$ См. Резолюцию ТАCA № 1055 (1995) от 2 февраля 1995 г.

4 См. Резолюцию ТАСА № 1065 (1995) от 27 сентября 1996 г.

s С.. Резолюцию ТACA № 193 (1996) от 25 января 1996 г. 
6 Подробнее см. Энтин М.Л. Международные гарантии прав чсловека (практика Совета Европы). - М.: Междунар. отношения, 1992. - 240 с.

${ }^{7} \mathrm{CM}$. Human rights - A confinuing challenge for the Connect of Europe. Stracbourg, Council of Europe Press. - P. 115-120.

8 Подробнес см. The European System for the Protection of Human Rigths/ Ed. by Macdonald R.St. J., Matscher F., Petzold H. - Dordrerect, Boston, London: Martinus Nighoff Publ., 1993. - 940 p.

9 Joint Programme between the Commussion of the European Communist and the Council of Europe for Strengthening of the Federal Structure Introduction of human rights profection pechanisms and legal system reform in the Russian Federation Strasbourg, November 1995.

${ }^{10} \mathrm{CM}$., например, Док. CE A8/Per (1996) 1 Propel d'ordre da jour de la deuxime partie de la session ordinanu de 1996 de l'Asseblei paslenenfaire (22-26 avril 1996).

1 См. Приложение к посланию Парламентской ассамблсе Совета Европы о совершенствовании российског законодательства и правоприменитепьной практики в соответствия со стандартами CE «Пояснение $\mathbf{k}$ состоянию и планам совершенствования правового порядка в Российской Федерации». - М., 1994.

Cтатья поступила в редакцию в мае 19962. 